\title{
LA LEGITIMACIÓN PASIVA DE LA ADMINISTRACIÓN MÉDICO-SANITARIA EN LA ERA DE LOS ESTABLECIMIENTOS AUTOGESTIONADOS EN RED
}

\author{
LEGAL STANDING FOR HEALTHCARE ADMINISTRATION IN THE \\ AGE OF SELF-MANAGED NETWORK ESTABLISHMENTS
}

Hugo A. Cárdenas VillarReal*

RESUMEN: El artículo aborda el problema de la legitimación pasiva cuando el daño se produce en el ámbito de acción de los llamados Establecimientos Autogestionados en Red. Se muestran las diferentes soluciones que le ha dado la jurisprudencia de los tribunales en los últimos años, y se aportan argumentos de carácter sustantivo y procesal en apoyo de la tesis que retiene la legitimación pasiva en los Servicios Públicos de Salud.

Palabras clave: Responsabilidad del Estado, responsabilidad médica, persona jurídica de derecho público, desconcentración de funciones, delegación, legitimación pasiva.

ABSTRACT: The article addresses the problem of passive legitimation when damage occurs in the scope of action of so-called Self-Managed Network Establishments. It shows the different solutions provided by the jurisprudence of the courts in recent years, and provides substantive and procedural arguments in support of the thesis that retains passive legitimation in the Public Health Services.

Keywords: Responsibility of the State, medical responsibility, juridical person of public law, deconcentration of functions, delegation, passive legitimation.

\section{INTRODUCCIÓN}

A finales del año 2011 publicamos los resultados de una extensa investigación jurisprudencial, donde perfilamos y comentamos los principales problemas del régimen que gobierna la responsabilidad patrimonial de la administración médico-sanitaria en Chile. Desde entonces, las grandes líneas jurisprudenciales que allí observamos se han mantenido constantes. Así, en términos generales, cuando se habla de la responsabilidad de los órganos del Estado que prestan servicios de salud, estamos hablando de una responsabilidad subjeti-

Abogado. Doctor en Derecho por la Pontificia Universidad Católica de Chile. Profesor de Derecho Civil de la Universidad de Chile. Dirección postal: Pío Nono 1, Providencia. Dirección de correo electrónico: hcardenas@derecho.uchile.cl. Agradezco a los profesores José Miguel Valdivia, Luis Cordero, José Ramón Gutiérrez y a la profesora Paulina González los comentarios que le hicieron a una versión inicial de este texto. También agradezco a los abogados Sebastián Flores y Felipe Lizama por haber discutido varias de las ideas que se exponen en este trabajo. 
va, por el hecho propio, que se atribuye a través de una categoría general (falta de servicio) que ha terminado por absorber todas las formas de imputar a los órganos del Estado que prestan servicios de salud ${ }^{1}$.

Aun así, desde que se publicara el trabajo referido, también se han producido algunos cambios relevantes en el régimen que gobierna la responsabilidad de la administración médico-sanitaria. Así, por poner algunos ejemplos, se observa que han aparecido nuevos tipos de conductas culposas (falta de información); nuevas categorías de daños indemnizables o formas de argumentación causal (pérdida de la oportunidad); y que se ha discutido la legitimación pasiva de los Servicios de Salud en el contexto de la entrada en funcionamiento de los Establecimientos Autogestionados en Red (en adelante EAR u Hospitales Autogestionados).

En este trabajo me ocuparé del problema de la legitimación pasiva en tanto que el tratamiento de este tópico interesa desde el punto de vista teórico, como desde el punto de vista práctico. Hoy en día, prácticamente no pueden encontrarse juicios donde no se haya presentado esta cuestión por vía de una excepción de legitimación pasiva perentoria o dilatoria, sin que la jurisprudencia haya logrado encontrar una solución uniforme.

Sostendremos la tesis de que el Servicio de Salud será el legitimado pasivo de la acción de perjuicios siempre que el daño se produzca en la esfera de control de un hospital que forme parte de su red, con independencia de que el hospital ostente (o no) la calidad de Autogestionado. Estructuralmente, el trabajo se divide en dos partes: en la primera, perfilaremos el problema separando la hipótesis conflictiva de aquellas otras en la que la legitimación pasiva no ha sido problematizada (I); y, en la segunda, abordaremos derechamente el problema de la legitimación pasiva del Servicio de Salud cuando el daño se causa en la esfera de control de un Establecimiento Autogestionado (II).

\section{EL PROBLEMA}

Así como los Servicios de Salud son organismos descentralizados de la Administración del Estado que constituyen la estructura fundamental de la administración médico-sanitaria, los hospitales públicos conforman el endoesqueleto de los Servicios de Salud ${ }^{2}$. Por lo mismo, la idea de que la legitimación pasiva le correspondía al Servicio de Salud cuando la actividad de estos hospitales causaba algún daño fue pacífica hasta que, por mandato de la ley, algunos de estos establecimientos experimentaron una desconcentración administra-

\footnotetext{
Cfr. CÁrdenas y Moreno (2011). El fundamento de esta falta de servicio evolucionó desde la clásica responsabilidad por el hecho ajeno propia del derecho civil, hasta la responsabilidad por el hecho propio por la deficiente organización del servicio, mediante el sistema de conceptos desarrollados en el seno de la teoría del órgano [HuEPE (2006) pp. 90 y ss.]. En esta evolución va perdiendo importancia la individualidad del funcionario que causó materialmente el daño, y se van echando los cimientos de un concepto omnicomprensivo de falta de servicio [Valdivia (2005) pp. 10 y ss.].

2 De acuerdo a los artículos 43 y ss. del Decreto Supremo $N^{\circ} 140$ (2005), el hospital (público) es el establecimiento destinado a proveer prestaciones de salud para la recuperación, rehabilitación y cuidados paliativos de personas enfermas y colaborar en las actividades de fomento y protección, mediante acciones ambulatorias o en atención cerrada. Al hospital le corresponderá otorgar, dentro de su ámbito de competencia, las prestaciones de salud que el Director del Servicio le asigne de acuerdo a las normas técnicas que dicte el MINSAL en la materia.
} 
tiva. Pero además del Servicio y de los Establecimientos Autogetionados, la administración médico-sanitaria incluye una amplia gama de entes administrativos centralizados y descentralizados; lo que obliga a quienquiera demandar una indemnización de perjuicios de la Administración, a determinar previamente cuál de estos órganos ostenta la legitimación pasiva, y quién se encuentra facultado legalmente para representarlos judicial y extrajudicialmente ${ }^{3}$.

\section{Los distintos Legitimados PASiVOS DEL SISTEMA CHILENO}

Respecto a la legitimación pasiva, si hasta hace algún tiempo advertíamos que quien estuviera por dirigir una demanda contra la Administración Médico-Sanitaria tendría que dirigirse (dependiendo de las particularidades del caso) hasta contra cuatro sujetos diferentes, hoy debemos señalar que las cosas han cambiado. En efecto, en los últimos años, los fallos de los tribunales de justicia han habilitado demandas hasta contra cinco diferentes órganos del Estado.

En primer lugar, será el Fisco el legitimado pasivo en los litigios en que se vea involucrado un órgano sanitario no personificado (ente centralizado o fiscal). La representación judicial en estos casos, le corresponde al presidente del Consejo de Defensa del Estado [artículo $18 \mathrm{~N}^{\circ} 1$ D.F.L. $\mathrm{N}^{\circ} 1$ (1993)] por tratarse de hospitales dependientes de ciertos organismos estatales carentes de personalidad y patrimonio propio (centralizados). En segundo lugar, se encuentran los Centros Asistenciales Experimentales, como el Hospital Padre Alberto Hurtado. Tales centros, así como la Dirección de Previsión de Carabineros de Chile y la Universidad de Chile (respecto de los hospitales y centros asistenciales que de ellos dependan), en su condición de organismos funcionalmente descentralizados, son sujetos pasivos de la acción de perjuicios en lugar del Servicio de Salud de la zona territorial de que se trate o, en su caso, del Fisco, puesto que están dotados de personalidad jurídica y patrimonio propio. En tercer lugar, en los daños que se producen como consecuencia de la actuación de los Servicios de Atención Primaria, la responsabilidad y la correspondiente legitimación pasiva le corresponde a la Municipalidad de la cual dependen, representada judicialmente por su Alcalde. En cuarto lugar, los Servicios de Salud detentarán la legitimación pasiva en los casos en que los hospitales y centros de salud (no personificados) dependientes de dicho servicio, ocasionen algún daño a sus usuarios. Estos hospitales y centros de salud, dependen jurídica y administrativamente del Servicio de que se trate y -en principio-, solo este último tiene el patrimonio y la titularidad jurídica para responder por los daños ocasionados por aquellos. La representación judicial y extrajudicial de los Servicios de Salud corresponde a su Director quien, además, es el Jefe Superior del Servició ${ }^{4}$.

La situación descrita se alteró a partir del año 2010 en tanto que Ley $\mathrm{N}^{\circ} 19.937$, de “Autoridad Sanitaria y Gestión” de 2005 (que modificó el D.L. № 2763, de 1979), prescribió que a partir de la fecha mencionada una gran cantidad de hospitales obtuvieran por

\footnotetext{
Sobre este y otros problemas procesales, GutiérREz (2009) pp. 245-279.
}

4 Artículo 6, D.S. No 140 (2005). Un tratamiento sistematizado de cada uno de los centros y hospitales que comprometen la responsabilidad de los diferentes legitimados pasivos mencionados puede verse en CÁRDENAS Y Moreno (2011). 
el solo ministerio de la ley la calidad de Establecimientos Autogestionados en Red. Como se verá enseguida, la especial regulación a la que fueron sometidos los EAR ha permitido levantar la tesis de la existencia de un quinto legitimado pasivo en el ámbito de acción de la administración médico sanitaria.

2. El PROBlema de la legitimación PASIVA DESDE la APARICIÓN EN ESCENA DE los HOSPITALES AUTOGESTIONADOS

Con la implementación del vigente diseño organizacional de los Servicios de Salud Pública se buscó dotar de un alto grado de autonomía a algunos hospitales públicos. Sin embargo, el legislador no consideró necesario conferirles personalidad jurídica, lo que ha generado dudas sobre cuál es el organismo que debe responder y, por consiguiente, una verdadera avalancha de excepciones dilatorias y perentorias de falta de legitimación pasiva en una gran cantidad de los juicios en que se busca la reparación los daños ocasionados por una mala práctica médica y hospitalaria.

\subsection{La configuración normativa de los EAR: un régimen legal muy poco claro}

Los Establecimientos de Autogestión en Red se encuentran regulados en el Título IV del Capítulo II, del D.F.L. N${ }^{\circ}$ (2005) del MINSAL, y en los Títulos I-VIII del D.S. Nº 38 (2005) del MINSAL, que establece el Reglamento Orgánico de los Establecimientos de Salud de Menor Complejidad y de los Establecimientos de Autogestión en Red ${ }^{5}$. Y, sin perjuicio de que algunos establecimientos adquirieron la categoría de autogestionados antes del 31 de enero de 2010 mediante resolución conjunta del Ministerio de Salud y Hacienda, desde esa fecha, los 56 hospitales que se indican en el artículo 15 transitorio de la Ley No 19.937 pasaron a tener la calidad de autogestionados, por el solo ministerio de la ley, desde el 31 de enero de 2010.

En lo medular, el artículo 31 incisos $1^{\circ}$ y $5^{\circ}$ del D.F.L. $\mathrm{N}^{\circ} 1$ (2005), dispone que los Hospitales Autogestionados en Red "serán órganos funcionalmente desconcentrados del correspondiente Servicio de Salud conforme al artículo 33 de la Ley 18.575 (...) No obstante, en el ejercicio de las atribuciones radicadas por ley en su esfera de competencia, no comprometerán sino los recursos y bienes afectos al cumplimiento de sus fines propios a que se refieren los artículos 42 y 43 (...) dentro de su nivel de complejidad, ejecutarán las acciones de salud que corresponden a los Servicios de Salud de acuerdo a la ley”. Y, al regular las atribuciones del Director del Establecimiento, el inciso final del artículo 36 de la misma norma dispone que, "para todos los efectos legales, la representación judicial y extrajudicial del Servicio de Salud respectivo se entenderá delegada en el Director del Establecimiento, cuando ejerza las atribuciones señaladas en este artículo", prescribiendo, en su inciso final, que "notificada la demanda, deberá ponerla en el plazo de 48 horas, en conocimiento personal del Director del Servicio de Salud correspondiente, quien deberá adoptar las medidas administrativas que procedieran y podrá intervenir como coadyuvante en cualquier estado del juicio".

El reglamento se encuentra en el Diario Oficial de 29 de diciembre de 2005. Como norma supletoria, se le aplica el Reglamento Orgánico de los Servicios de Salud, contenido en el Decreto Supremo No 140 (2005). 
Básicamente, el hecho de que se afectaran bienes al cumplimiento de los fines propios de los Establecimientos Autogestionados en el contexto de una desconcentración funcional, es lo que ha permitido que el Ministerio de Salud impulsara la interpretación que concibe como legitimados pasivos, en el lugar de los Servicios de Salud, a los Establecimientos Autogestionados. Así, mediante la circular $N^{\circ} 1$ de la Subsecretaría de Redes Asistenciales, de 29 de febrero de 2008, el Ministro de Salud $(S)^{6}$ impartió instrucciones en materia de representación judicial de los EAR, en los siguientes términos: "se deduce claramente, que la representación judicial del Establecimiento corresponde por ley a su Director, al que compete asumir -en su caso- las correspondientes acciones para su defensa, y que en caso de acciones judiciales dirigidas contra el Establecimiento el resultado de las mismas solamente compromete los bienes y recursos del mismo, no implicando, en ningún caso, los bienes del respectivo servicio de Servicio de Salud. Sin perjuicio, por cierto, que el Director del Servicio pueda, si lo estima conveniente, intervenir como tercero coadyuvante en dichos juicios".

Pero esta interpretación de la Subsecretaría de Redes Asistenciales y la posición de un trabajo doctrinal reciente ${ }^{7}$ parecen haber ido demasiado lejos, ya que tanto la normativa vigente, como los desarrollos del derecho sustantivo y procesal parecen indicar que el legitimado pasivo (el obligado a la deuda) sigue siendo el Servicio de Salud. Respecto de la cuestión planteada, ya nos habíamos mostrado favorables a mantener la legitimación pasiva en el Servicio de Salud ${ }^{8}$ y 'en una recientísima obra', PIZARRO 9 parece compartir esta postura. Sin perjuicio de lo anterior, los argumentos que fundamentan esta posición no han sido completamente explicitados y, como veremos enseguida, la jurisprudencia se encuentra dividida.

\subsection{La jurisprudencia que considera al hospital como legitimado pasivo}

Respecto de esta tendencia jurisprudencial puede verse Saldías Araya Elsa Pablina y otros con Servicio de Salud Metropolitano Oriente y otros ${ }^{10}$. En el caso se demandó conjuntamente al Servicio de Salud, al Hospital Santiago Oriente Dr. Luis Tisné Brousse y al Instituto de Neurocirugía Dr. Alfonso Asenjo, por el retraso en la realización de una trombólisis. En primera instancia, se condenó de forma solidaria a los demandados y, apelado el fallo, la Corte de Apelaciones de Santiago revocó la condena del Servicio de Salud señalando "que de acuerdo al artículo 35 del D.F.L citado, 'La administración superior y control del Establecimiento corresponderán al Director. El Director del Servicio de Salud

\footnotetext{
Ministerio de Salud, Subsecretaria de Redes Asistenciales, Departamento de Asesoría Jurídica.

$\mathrm{Al}$ respecto, la autora afirma que "... a diferencia de lo que sostiene la doctrina, son los propios Hospitales Autogestionados y no los Servicios de Salud, quienes detentan la legitimación pasiva en las acciones de responsabilidad por falta de servicio y la titularidad jurídica para responder patrimonialmente por las indemnizaciones compensatorias de perjuicios". Véase CarVajal (2014) pp. 138 y 139.

8 Cárdenas y Moreno (2011) p. 14.

9 Pizarro (2017) p. 155.

10 Saldís Araya Elsa Pablina y otros con Servicio de Salud Metropolitano Oriente y otros (2016). Duodécima Sala de la Corte de Apelaciones de Santiago, integrada por los Ministros Sr. Alfredo Pfeiffer R., Sr. Fernando Carreño O. y Sra. Patricia Liliana González Q. En el mismo sentido, puede verse ARAYA CASTILLO CON SERVICIO DE SALUD II REGIÓN DE ANTOFAGASTA (2015).
} 
no podrá interferir en el ejercicio de las atribuciones que le confiere este Título al Director del Establecimiento, ni alterar sus decisiones...'. A su vez, el artículo 36 dispone que 'En el Director estarán radicadas las funciones de dirección, organización y administración del correspondiente Establecimiento y en especial tendrá las siguientes atribuciones: a) Dirigir la ejecución de los programas y acciones de salud y coordinar, asesorar, inspeccionar y controlar todas las dependencias del Establecimiento' (...) Que, de una correcta interpretación de las normas antes señaladas, aparece que el Servicio de Salud Metropolitano Oriente carece de legitimación pasiva para responder de los hechos en que se fundó el libelo pretensor" (considerandos $2^{\circ}, 4^{\circ}$ y $5^{\circ}$ ).

El hospital y el instituto condenados interpusieron un recurso de casación en la forma por infracción al artículo $768 \mathrm{~N}^{\circ} 4$ del Código de Procedimiento Civil, sin que a la fecha haya sido resuelto por la Corte (el fallo se encuentra en acuerdo desde el 4 de julio de 2017) ${ }^{11}$. A diferencia de los otros fallos que se manifiestan en favor de la legitimación pasiva del Hospital Autogestionado cuando solo se ha demandado a uno de estos establecimientos, en este caso el problema se plantea en toda su extensión, puesto que se demandó y condenó solidariamente al hospital y al Servicio en primera instancia. Por lo tanto, al resolver el recurso de casación referido, la Corte Suprema tiene que definir cuál de los dos órganos es el legitimado pasivo sin atender a más consideraciones que la corrección dogmática de su decisión.

Por su parte, al menos en una ocasión, la Corte Suprema ha avalado la tesis de la legitimación pasiva del Autogestionado. Así, en Muñoz Torres y otro con Hospital Base Puerto MontT ${ }^{12}$ se demandó al Hospital Base Puerto Montt (notificándose la demanda a su Director) y se acogió la acción, siendo el fallo confirmado por la Corte de Apelaciones. Ante esto, la defensa del Hospital interpuso un recurso de casación en la forma y el fondo donde, en lo pertinente a este trabajo, se sindicó en el fondo al artículo 36 del D.F.L. $\mathrm{N}^{\circ} 1$ (2005), por cuanto este solamente confiere al Director del establecimiento demandado la representación judicial para efectos de las atribuciones contenidas en dicho artículo, dentro de las cuales no se encuentra la de ser emplazado y comparecer en juicios indemnizatorios como el presente.

Resolviendo el recurso, la Corte Suprema afirmó que "en tanto establecimiento autogestionado, el Hospital Base de Puerto Montt es representado judicialmente por su Direc-

\footnotetext{
11 A efectos de su seguimiento, puede consultarse el recurso en rol No 11759-2017 de la Corte Suprema.

12 Muñoz Torres y otro con Hospital Base Puerto Montt (2016). Tercera Sala de la Corte Suprema, integrada por los Ministros Sr. Sergio Muñoz G., Sr. Haroldo Brito C., Sra. María Eugenia Sandoval G. (redactora), Sr. Carlos Aránguiz Z., y Sr. Manuel Valderrama R.

Existen otros casos en que la Corte ha confirmado que la legitimación pasiva es del hospital, pero generalmente se trata de supuestos en que rechaza el recurso por razones de forma o, derechamente, en casos en que no debía siquiera entrar al problema debido a que los hechos que provocaron el litigio se produjeron antes de que el hospital en cuestión se transformara en Autogestionado. En este sentido, puede verse CAMPOS GODOY ROdrigo-Campos Godoy Braulio-Campos Godoy Daniel con Servicio de Salud Metropolitano (2015). En Arrau Henriquez con Hospital del Salvador, Servicio de Salud Metropolitano (2016), la Corte Suprema refiere constantemente que no se invocaron las leyes que regulan el gobierno de los Establecimientos Autogestionados no obstante que ello era impertinente, pues los hechos se produjeron antes de que el establecimiento en cuestión alcanzara el estatus de Establecimiento Autogestionado.
} 
tor, quien goza de las atribuciones y personería suficientes para ser emplazado y comparecer en el presente juicio indemnizatorio, de manera que tampoco se aprecia la existencia de la transgresión reprochada" (considerando $20^{\circ}$ ). El fallo no presenta un gran desarrollo argumentativo, pero debe mencionarse en tanto que sostiene una de las soluciones posibles.

\subsection{Jurisprudencia que concibe al servicio de salud como legitimado pasivo}

La jurisprudencia que mantiene la legitimación pasiva en el Servicio de Salud discurre por dos cauces argumentativos diferentes. Por un lado, están los fallos que entienden que la norma que delega la representación en el Director del hospital constituye una forma de emplazar al Servicio, quien siempre conservará la legitimación pasiva (2.3.1); y, por otro, están los fallos que entienden que la delegación de la representación no incluye la facultad de representar al Servicio en juicios de perjuicios, por lo que en casos de juicios resarcitorios será el Servicio el legitimado pasivo, debiéndose emplazar por medio de su Director (2.3.2).

\subsubsection{La delegación de la representación constituye una forma de emplazamiento}

Respecto del primer cauce argumentativo referido, en LEPE ALARCON CON HOSPITAL SAN JOSÉ CORONEL ${ }^{13}$, el paciente fue sometido a cirugía para tratar una hernia umbilical. La cirugía no salió según lo esperado y el señor Lepe Alarcón interpuso una demanda en contra del Servicio de Salud de Concepción, notificando a su Director. El Servicio, a su vez, interpuso una excepción dilatoria de falta de legitimación pasiva que fue acogida, ordenando el tribunal que se notificara a quien en derecho correspondiere ${ }^{14}$. En lugar de ello, el señor Lepe Alarcón presentó una nueva demanda, ahora en contra del Hospital San José de Coronel, notificando a su Director.

Curiosamente, esta última demanda es contestada por el Servicio de Salud de Concepción, quien interpuso una excepción perentoria de falta de legitimación pasiva. El fallo de primera instancia acogió dicha excepción perentoria y rechazó la demanda arguyendo "[q]ue la legitimación pasiva recae en el Servicio de Salud Concepción, organismo que cuenta por personalidad jurídica, pero representada para estos efectos por el Director del Hospital San José de Coronel, establecimiento autogestionado en red; no pudiendo afirmarse, por tanto, que esta legitimación recae en el Hospital San José de Coronel representado por su director el Dr. Hugo Arce Rebolledo"15. Apelado el fallo, la Corte de Concepción confirmó la sentencia de primer grado, no interponiéndose en esta causa recurso de casación.

\footnotetext{
13 Lepe Alarcón con Hospital San José Coronel (2015). Quinta Sala de la Corte de Apelaciones de Concepción, integrada por los Ministros Sr. Jaime Solís P., Sr. César Panés R. y Sra. Valentina Salvo O. En contra de esta sentencia no se interpuso recurso alguno.

14 Lepe Alarcón con Servicio de Salud Concepción (2013). Primer Juzgado Civil de Concepción.

15 Lepe Alarcón con Hospital San José Coronel (2015).
} 
Dentro de la misma línea argumentativa, en DE LA FUENTE GOMEZ CON SERVICIO DE SALUD CONCEPCIÓN ${ }^{16}$, la Corte de Apelaciones de Concepción (resolviendo una apelación incidental), estimó que en caso de un Establecimiento Autogestionado “...la representación judicial y extrajudicial que corresponde al Servicio de Salud se entiende delegada, por el solo ministerio de la ley, en el Director del Hospital Autogestionado, conforme al artículo 36 inciso final del DFL 1 de 2005, Ministerio de Salud, lo que en la especie viene a significar que la demanda de indemnización de perjuicios debió dirigirse y notificarse legalmente al Director de dicho Hospital, y no al Director del Servicio de Salud, como realmente se hizo”. En razón de lo anterior, la Corte revocó la resolución apelada, acogió la excepción dilatoria deducida y resolvió que debe "dirigirse la acción en contra del Servicio de Salud de Concepción, representado legalmente por el Director del Hospital Guillermo Grant Benavente de Concepción". En el caso no se interpusieron recursos de casación.

Como se verá en la segunda parte de este trabajo, esta tendencia jurisprudencial es la que nos parce más acorde con la regulación vigente y con los desarrollos del derecho sustantivo y procesal.

\subsubsection{La delegación de la representación no incluye los juicios de perjuicios}

Respecto de la segunda variante referida para retener la legitimación pasiva en el Servicio (la delegación de la representación judicial y extrajudicial regulada por el artículo 36 no incluye la facultad de representar al Servicio en juicios de perjuicios), puede verse GonzÁlez CON SERVICIO de SALUd METROpolitano OCCIDENTE ${ }^{17}$. En este caso, el demandante sufrió un accidente automovilístico y fue llevado a la posta del Hospital de Melipilla, donde fue dado de alta a las 12:30 horas sin indicaciones ni medicamentos. A las 15:30 del día siguiente el paciente volvió a ingresar al Hospital donde se iniciaron una serie de derivaciones al cabo de las cuales terminó con una tetraparesia severa. A consecuencia de estos hechos se demanda al Servicio de Salud Metropolitano Occidente (notificando a su Director), quien interpuso la excepción dilatoria de falta de legitimación pasiva.

En primera instancia se acogió tal excepción, y se ordenó que se efectuara la corrección del procedimiento. Apelado el fallo, la Corte de Apelaciones de Santiago lo revocó, pronunciándose en los siguientes términos: “(...) las atribuciones que establece el artículo 36 del referido D.F.L respecto del Director del Establecimiento, no alteran lo antes señalado, toda vez que dicha norma solo tuvo como objetivo dotar a los órganos autogestiona-

\footnotetext{
16 De la Fuente con SeRVicio de SALUd ConcepCión (2015). Cuarta Sala de la Corte de Apelaciones de Concepción, integrada por los Ministros Sr. Freddy Vásquez Z., Sr. Juan Villa S. y el Abogado Integrante Sr. Mauricio Ortiz S. En la misma lógica, puede verse Pareja CEBallos con SERVICIO de SALUd TalCahUano (2014). En contra de ninguna de estas sentencias se interpuso recurso alguno.

17 GonzAlez con SerVicio de SALUd Metropolitano OcCidente (2016). Segunda Sala de la Corte de Apelaciones de Santiago, integrada por los Ministros Sr. Mario Rojas G., Sra. Viviana Toro O. y la Ministra (S) Sra. Ana María Hernández M. En contra de esta sentencia no se interpuso recurso alguno.

En el mismo sentido, puede verse: TRIVIÑo GutiéRrez Jorge con SERVICIO de SALUd deL ReLONCAVI (2015) y Carcamo Alarcón Juan Carlos con Servicios de Salud (2014) y García Rivera y otra con SerVicio de Salud Metropolitano Oriente, Hospital Luis Calvo Mackenna y Luis Tisné (2014). En contra de ninguna de estas sentencias se interpuso recurso alguno.
} 
dos de mayor independencia en materias de gestión administrativa y presupuestaria, y en consecuencia, lo fue para el cumplimiento de sus fines específicos, esto es, la gestión de sus propios recursos para el cumplimiento de sus fines. Tan es así, que el mismo artículo 36 antes referido establece en su inciso final que 'Para todos los efectos legales, la representación judicial y extrajudicial del Servicio de Salud respectivo se entenderá delegada en el Director del Establecimiento, cuando ejerza las atribuciones señaladas en este artículo’, esto es, las gestiones señaladas anteriormente" (considerando $4^{\circ}$ ).

Esta posición jurisprudencial (que podría denominarse restrictiva) parece ir en la dirección correcta en cuanto mantiene la coherencia al retener la legitimación pasiva en el órgano que tiene personalidad jurídica y patrimonio propio, pero evidencia problemas en cuanto no logra fundamentar por qué algunas facultades estarían delegadas y otras no (la de representar al órgano en juicios indemnizatorios).

\section{EL SERVICIO DE SALUD COMO SUJETO PASIVO DE LAS ACCIONES DE REPARACIÓN DE DAÑOS OCASIONADOS POR EAR}

La personalidad de derecho público ha sido comprendida tradicionalmente como un requisito para contar con capacidad en el proceso, sin embargo, esta comprensión ha sido cuestionada por una práctica que ha prescindido (en algunos casos) de la personificación del órgano en el otorgamiento de la capacidad para ser parte en el juicio, como para actuar en él ${ }^{18}$. Así las cosas, podría pensarse que el problema de la legitimación pasiva de los Establecimientos Autogestionados es un supuesto paradigmático para explicar esta evolución en tanto que se trata de órganos no personificados que, aparentemente, contratan en nombre propio. Sin embargo, en nuestra opinión, una correcta interpretación de la normativa que organiza el Servicio de Salud en Chile impide llegar a esa conclusión. En lo que sigue, se expondrán los fundamentos sustantivos (1) y procesales (2) que apoyan esta posición.

\section{Fundamentos Sustantivos de la tesis de la legitimación PASIVA DEL SERVICIO}

\subsection{ANÁLISIS Y RECHAZO DEL ARGUMENTO DE LA "PERSONALIDAD DELEGADA"}

No obstante que la cuestionable técnica legislativa utilizada en esta regulación ha provocado múltiples escaramuzas argumentativas, cuando se analiza el tratamiento que se le ha dado al problema de la legitimación pasiva, se advierte que el primer obstáculo que intentan salvar los que defienden la legitimación de los Autogestionados, es la falta de personalidad jurídica que exhiben los mismos. De ello deriva que el principal argumento de los que defienden esta tesis es el que llamaremos, a falta de una mejor denominación, el razonamiento de la "descentralización por analogía".

Sintéticamente, el argumento sostiene que la desconcentración administrativa que se llevó a cabo mediante el D.F.L. No 1 (2005) de los Hospitales Autogestionados se hizo de tal manera que produce los mismos efectos que una descentralización. Según esta tesis, la Ley de Autoridad Sanitaria introdujo tres variaciones a la tradicional forma de constitu-

18 Véase Gutiérrez (2009). 
ción de un Servicio funcionalmente desconcentrado, lo que permite concebirlo de una manera diferente. En términos explícitos, la doctrina que defiende esta tesis sostiene que "la especial desconcentración administrativa prevista por la Reforma dota a los Hospitales Autogestionados de una organización propia para gestionar independientemente el conjunto de competencias, el recurso humano y los medios materiales adscritos al servicio público, constituyéndolos en un centro de imputación de relaciones jurídicas pero sin llegar a personificarlos, sin crear una 'autonomía funcional', rasgos conceptuales que se confunden con aquellos distintivos de los entes descentralizados"19.

Consecuentemente con lo anterior, la citada doctrina postula que "el modelo de gestión hospitalaria seguido por la Ley de Autoridad Sanitaria que dispuso a los Hospitales Autogestionados integrando la persona jurídica del Servicio de Salud, pero dotándolos a la vez de personalidad jurídica delegada para el ejercicio de sus atribuciones, de un presupuesto y un patrimonio de afectación destinado al cumplimiento de sus fines propios, nos permite deducir que son los Hospitales Autogestionados los que poseen la legitimación pasiva en las acciones de responsabilidad por falta de servicio así como la titularidad jurídica para responder patrimonialmente por las indemnizaciones compensatorias de perjuicios" ${ }^{20}$.

En los términos expuestos, la tesis difícilmente puede aceptarse, puesto que las tres premisas que se utilizan para "deducir" la conclusión (en realidad se trata de un razonamiento inductivo por analogía) de que los Establecimientos Autogestionados ostentan la legitimación pasiva y la titularidad jurídica para responder patrimonialmente, son falsas o incorrectas.

En efecto, cuando se dice que la ley concibió a los hospitales integrando la persona jurídica del Servicio de Salud, "dotándolos a la vez de personalidad jurídica delegada", se incurre en una contradicción en sus propios términos. Ello porque se tiene personalidad $y$, por lo mismo, se es independiente; o no se tiene, y, en consecuencia, se actúa en el marco de personalidad jurídica del órgano que la tiene. Además, se incurre en un grave error conceptual cuando se afirma que se "dotó" a los establecimientos de "personalidad jurídica delegada", sobreinterpretando la norma del artículo 36 del D.F.L No 1 (2005) que simplemente consignó la representación del Servicio en los siguientes términos: "la representación judicial y extrajudicial del Servicio de Salud respectivo se entenderá delegada en el Director del Establecimiento, cuando ejerza las atribuciones señaladas en este artículo”.

La segunda premisa de la que se vale la tesis de la descentralización/legitimación analógica (dotación presupuestaria), tampoco parece del todo correcta. Y es que, no obstante que cada Establecimiento Autogestionado deberá tener un presupuesto, este deberá ser presentado ante el Director del Servicio para que lo informe y lo remita al Subsecretario de Redes Asistenciales. Luego, sobre la base del presupuesto que se le haya aprobado al Servicio de Salud correspondiente, y las instrucciones que imparta la Dirección de Presupuestos, el Subsecretario aprobará, mediante resolución, los presupuestos de los Establecimientos Autogestionados (artículo 36, letra d). Como se ve, el órgano que tiene la asignación en la Ley de Presupuesto es el Servicio de Salud, y de ese presupuesto se destina una parte al pre-

19 Carvajal (2014) p. 146.

20 Carvajal (2014) p. 146. 
supuesto de cada uno de los Establecimientos Autogestionados de su Red. La participación del Subsecretario, más que mostrar la autonomía de estos establecimientos, evidencia la dependencia fáctica a la que están sometidos los Servicios de Salud respecto de la Administración Central.

Respecto a la afectación de recursos y bienes que hace la ley al cumplimiento de los fines propios de los Establecimientos Autogestionados (artículo 31), lo cierto es que la redacción del artículo 43 genera un severo problema interpretativo al referir que "el Establecimiento tendrá el uso, goce y disposición exclusivo de los bienes raíces y muebles de propiedad del Servicio de Salud correspondiente, que se encuentren destinados al funcionamiento de los servicios sanitarios, administrativos u otros objetivos del Establecimiento..." (artículo 43, inciso 1). Pero dado que la norma expresa que se destinan bienes de propiedad del Servicio al funcionamiento del Establecimiento, parece claro que el patrimonio no es de dicho Establecimiento.

No obstante la oscura redacción de la norma, no puede lógicamente pensarse que se trata de un patrimonio de los Establecimientos Autogestionados, puesto que no son Servicios Públicos autónomos, "por lo que no cuentan con personalidad jurídica ni patrimonio propio" 21 . Nos parece que la idea de un Servicio propietario, y un Establecimiento que tiene todos los atributos del dominio sobre los bienes propiedad del Servicio que le son destinados para el cumplimiento de los fines, solo se explica si se entiende que es la misma persona y que simplemente se está distribuyendo patrimonio para fines administrativos. El ordenamiento chileno contempla otras afectaciones patrimoniales similares, sin que por ello se haya entendido que el órgano descentralizado pierde la legitimación pasiva ${ }^{22}$. Así las cosas, en lugar de un patrimonio propio, se trata de un patrimonio del Servicio que se destina a una determinada función que se desconcentra. Lo anterior es concordante con lo consignado en la Historia de la Ley $\mathrm{N}^{\circ} 19.937$, específicamente en lo expuesto por el Ministro de Salud, Sr. Artaza, al señalar que "existe voluntad del Ejecutivo para que los Hospitales Autogestionados mantengan la calidad de tales durante un período determinado, otorgándoles, además, algún grado de manejo presupuestario, pero con un patrimonio perteneciente al Servicio de Salud respectivo" ${ }^{23}$.

Como se ve, el presupuesto de identidad entre los caracteres de un órgano descentralizado y los de los Establecimientos Autogestionados del que parte la tesis que retiene la legitimación pasiva en los Establecimientos es incorrecto o, al menos, muy discutible. Si ello es así, desde el punto de vista lógico-argumentativo, el razonamiento por analogía que hace la doctrina que defiende la legitimación pasiva del Establecimiento sencillamente no se puede aceptar.

21 Nancuante et al. (2012) p. 164.

22 Un buen ejemplo de lo dicho es la Resolución EXENTA No 566, que Delega facultades del Director de DIPRECA en el Director del Hospital DIPRECA.

23 Biblioteca del Congreso Nacional (2004) p. 572. 


\subsection{LAS RAZONES DE FONDO QUE APOYAN LA LEGITIMACIÓN PASIVA DEL SERVICIO}

Aparte de los problemas lógicos que evidencia la fundamentación de la tesis que defiende la legitimación pasiva de los Establecimientos Autogestionados, la tesis de la legitimación pasiva del Servicio es más acorde con la doctrina administrativa y la regulación chilena (1.2.1), y con los principios que gobiernan la reparación de los daños en nuestro sistema jurídico (1.2.2).

\subsubsection{El problema de la legitimación pasiva desde los desarrollos del derecho administrativo}

No obstante que en el ordenamiento jurídico chileno no es habitual que dentro de organismos descentralizados se configuren potestades desconcentradas, tampoco puede decirse que se trate de una cuestión extraña. Así, por vía de ejemplo, pueden verse organismos descentralizados que se desconcentran territorialmente, como la Superintendencia de Educación ${ }^{24}$, así como en organismos descentralizados que se desconcentran funcionalmente, como las Municipalidades.

Por su parte, la doctrina administrativa chilena trata la desconcentración administrativa en el marco del estatuto regional que fue establecido por la Carta Fundamental de 1980 (extendido a partir de la Ley de Reforma Constitucional $\left.N^{\circ} 19.097\right)^{25}$, y de la regulación contenida en la Ley Orgánica de Bases Generales de la Administración del Estado. La desconcentración (artículo $3^{\circ}$ de la Constitución Política), se concibió como una forma de asignar atribuciones a un órgano inferior para que pudiera gestionar y decidir sobre un conjunto de materias, manteniendo la supeditación jerárquica respecto del órgano superior. Este último órgano podrá impartir criterios generales de acción, aunque sin arrogarse la resolución de aquellos negocios confiados al inferior ${ }^{26}$. La idea de que la desconcentración tiene por objeto racionalizar y dinamizar la Administración al contar con una mejor y más expedita organización, es comúnmente compartida por la doctrina chilena ${ }^{27}$.

Respecto del problema de la personificación del órgano desconcentrado, también hay un acuerdo generalizado en que los órganos desconcentrados no constituyen una persona jurídica autónoma. Este no deja de pertenecer a la persona jurídica que integra y se encuentra en relación de subordinación respecto del organismo del cual se desconcentra, con independencia de la teoría que se use para explicar la naturaleza jurídica de la desconcentración (transición a la descentralización, limitación jerárquica, variante de centralización,

\footnotetext{
24 Véanse los artículos 47 y 101 de la LeY No 20.529 (2011).

25 Uno de los últimos trabajos con referencias históricas al establecimiento de la normativa constitucional es de Alarcón (2015) pp. 5-11. A su vez, desde la perspectiva del ordenamiento territorial y sus instrumentos, puede consultarse el trabajo de PRECHT et al. (2017). Por otra parte, se han tenido en vista para esta explicación, Sото (1992) pp. 103-125, у Sото (1989) pp. 115-147; ambos reproducidos igualmente en Sото (2009) pp. 154-196. Sobre la desconcentración también puede verse Bermúdez (2014) pp. 366-370. En su origen histórico y explicación referida a la L.R.C. N 19.097, véase TOBAR (2012) pp. 214-237. Finalmente, tratando la naturaleza del estado regional, las competencias de las regiones y la estructura del municipio, entre otros, consúltese a CEA (1999) pp. 286-329.

26 SiLVA (1997) p. 84

27 Por todos, Fernández (1981) p. 209.
} 
elemento técnico organizativo para evitar la burocracia o de distribución de competencias ${ }^{28}$. El tema también es relativamente pacífico en la jurisprudencia de los tribunales de justicia, al menos cuando examinan otros ámbitos de la Administración del Estado. Así, en un fallo de la Sala Tercera de la Corte Suprema, de 19 de enero de 2015, en el que se analizaba la legitimación pasiva del Servicio de Evaluación de Impacto Ambiental, sencilla y simplemente se afirmó que "los procedimientos contenciosos administrativos no hacen excepción a la regla básica de que solo los organismos de la Administración que poseen dicha personalidad pueden ser llevados a juicio". Y, en un comentario a este fallo, CORDERo llama la atención sobre la importancia del concepto de la personalidad jurídica a la hora de demandar a los organismos de la Administración, sosteniendo que "en el caso Mina Invierno la Corte contribuye a despejar esa recurrente confusión entre órgano y organismo. Para ella, el mecanismo que permite ordenar el litigio público es la personalidad jurídica en donde se insertan los órganos respectivos. Y esto es algo que deben tener presente cuando demanden a los organismos de la Administración del Estado"29.

Desde el punto de vista técnico, la desconcentración funcional que experimentaron los Servicios de Salud no es muy diferente a lo que ocurre con una desconcentración estándar, con la salvedad de que cierta atribución del Director del Servicio de Salud (representación judicial y extrajudicial) fue delegada por expreso mandato de la ley en el Director de los Hospitales Autogestionados, para darles mayor autonomía en la administración de los recursos que se necesiten para la prestación de las acciones de salud. Adviértase, sin embargo, que la delegación de la representación judicial y extrajudicial que tiene el Director de un organismo descentralizado en el Director de un órgano desconcentrado (o de otro tipo) tampoco es extraña en el ámbito chileno, y no ha sido un instrumento por medio del cual estos órganos hayan absorbido la legitimación pasiva ${ }^{30}$.

La delegación administrativa tiene como presupuesto que el ejercicio de la competencia constituye una obligación improrrogable de la autoridad, a menos que esta estuviere expresamente autorizada. Cuando ello sucede, las atribuciones del órgano superior pasan al inferior, quien realizará los actos correspondientes haciendo constar expresamente que los adoptará por tal delegación. Por lo mismo, puede afirmarse que "los actos emitidos por el órgano delegado se considerarán como si hubieran sido emitidos por el órgano delegante"31. La delegación así concebida tiene consagración expresa en el artículo 43 de la LOCBGAE (con los requisitos que allí se señalan).

Huelga señalar que ambos mecanismos de atenuación de efectos de la centralización (desconcentración y delegación), se enmarcan dentro del concepto de organización administrativa, entendido como el conjunto de normas jurídicas que regulan la competencia, las relaciones o vínculo de jerarquía, la situación jurídica, las formas de actuación y el control de los órganos y demás servicios públicos en el ejercicio de la función administrativa que

28 Sobre la explicación de cada una de estas teorías, consúltese a ARGANDOÑA (1982) pp. 95 y 96. En el ejercicio de su función desconcentrada se actúa con competencia propia, como las representaciones regionales de los servicios públicos. Sobre este último punto, véase CORDERO (2015) pp. 122 y 123.

29 Cordero (2015) p. 1.

30 Véase n. 22. Algunas críticas pueden verse en Inostroza y Nancuante (2013) p. 54.

31 FERnÁNdeZ (1981) p. 195. 
les haya sido asignada ${ }^{32}$. Se trata de un marco de encuadramiento y referencia de empleo de personas jurídicas cuyas acciones se imputan a aquella, la que proporciona medios materiales y económicos para desarrollar sus labores, resultando ser centros de imputación de relaciones jurídicas, sin tener una capacidad civil general para operar en el tráfico jurídico sino una habilitación (deber de actuación que emana de las potestades atribuidas por el ordenamiento) ${ }^{33}$. Así entendida, tiene varios objetivos, entre ellos, conformar la capacidad jurídica de cada entidad administrativa, definiendo sus fines y distribuyendo las competencias administrativas entre todas ellas y entre sus órganos, sumado el de la atribución de medios personales, materiales y financieros ${ }^{34}$.

Como puede apreciarse de la referencia anterior, los instrumentos señalados no sirven para generar un ámbito de capacidad jurídica como el que puede desprenderse del artículo 545 del Código Civil, que trata la materia. En otras palabras, ambos mecanismos suponen que el órgano con las nuevas atribuciones, potestades o funciones, tiene un superior que (con capacidad) puede responder por las actuaciones de dicho órgano, y que por razones que pondera el Legislador o la Administración, otorga potestades específicas de las que puede ejercer un poder jerárquico o, en su defecto, prescindir de él ${ }^{35}$.

\subsubsection{El problema de la legitimación pasiva desde la óptica del derecho de daños}

El principio de reparación integral prescribe que el perjuicio es el límite de la reparación. Se trata de un principio que forma parte del sistema de responsabilidad civil y, más ampliamente, del sistema general de reparación del daño ${ }^{36}$. En virtud del mismo, cualquier obstáculo a la reparación del perjuicio debe ser removido, lo que nos lleva (en el caso que aquí tratamos) a rechazar la interpretación que le asigna la legitimación pasiva a los Establecimientos Autogestionados. Lo anterior, aun dejando de lado el déficit de constitucionalidad que tendría cualquier norma que coloque un tope máximo a la indemnización en el ordenamiento jurídico chileno ("solo comprometerá esos bienes"), porque en la práctica no es fácil saber cuáles hospitales han alcanzado el estatus de Autogestionados; y porque la difícil situación financiera que exhiben muchos de estos Establecimientos al día de hoy, podría imposibilitar o retardar injustificadamente el derecho de las víctimas a ser resarcidas.

\footnotetext{
32 Ponce de León (2015) p. 47.

33 Parejo (2016) p.193.

34 Ponce de LeÓn (2015) p. 46. Santa María Pastor denomina a la delegación y la desconcentración (junto con otros mecanismos propios de España) como las "traslaciones competenciales". Su explicación, con base al régimen español y con referencias a la normativa comunitaria europea, en SANTA MARía (2016) pp. 387-402. El mismo Parejo advierte que a toda organización es inherente la potestad de organización, que da lugar a los mecanismos que estamos pasando revista [PAREjo (2016) p. 198]. Véase el tratamiento dogmático de la cuestión en Parejo (2016) pp. 209-214.

35 Ello no obsta a que, en Chile, de manera excepcional, se haya admitido en sede jurisprudencial que ciertos entes sin personalidad jurídica y que participan de la persona del Fisco puedan comparecer en ciertos negocios ventilados ante tribunales, como es el caso del recurso de protección de garantías constitucionales del artículo 20 de la Constitución, en cuanto se dirige en contra de organismos que son parte de otra persona jurídica y comparecen en actuaciones procesales. Sobre este tema, véase GuTIÉRrEZ (2009) pp. 264, 265 y 268.

36 Domínguez (2010) p. 9.
} 
Respecto del primer punto, no hay duda de que la incerteza sobre la cantidad e identidad de los Establecimientos que integran un Servicio de Salud, afecta la protección de los demandantes si, al mismo tiempo, prima una interpretación que apoya la idea de que, en algunos casos, la legitimación corresponderá al Servicio (Establecimientos no Autogestionados); mientras que, en otros, al Establecimiento (Autogestionado). La norma que reguló la forma en se adquiere la categoría de Autogestión en Red es el artículo $25 \mathrm{~A}$ de la Ley $\mathrm{N}^{\circ}$ 19.937 de Autoridad Sanitaria y Gestión ${ }^{37}$. Según esta disposición, la categoría se obtendrá mediante una resolución conjunta de los Ministerios de Salud y Hacienda, una vez que se acreditare el cumplimiento de una serie de requisitos. No obstante lo anterior, la ley prescribió que cincuenta y seis Establecimientos pasarían a tener la calidad de Autogestionados, por el solo ministerio de la ley, desde el 31 de enero de 2010 (artículo 15 transitorio) ${ }^{38}$.

Con la regulación referida, algunos establecimientos obtuvieron la calidad de Establecimientos Autogestionados en Red en el periodo que va desde el año 2006 hasta el 31 de enero de $2010^{39}$; otros (la mayoría) la obtuvieron por el solo ministerio de la ley el 31 de enero de 2010; mientras que otros la han obtenido con posterioridad a esa fecha ${ }^{40}$. El tema resulta de extraordinaria importancia porque no existe un registro que permita saber con seguridad cuáles hospitales ostentan la calidad; y porque, aunque se admita que los hospitales tienen la legitimación pasiva, ello solo sería así en casos en que el daño se hubiese ocasionado con posterioridad a su calificación como Autogestionados. Respecto de los casos anteriores a ese momento, no se discute la legitimación pasiva del Servicio.

En la situación actual, no es fácil determinar si el Establecimiento ostenta la calidad de Autogestionado o no, y el análisis de la jurisprudencia evidenció que el tema de las fechas en que los hospitales obtuvieron la categoría de Autogestionados es prácticamente desconocido por los operadores del sistema (jueces y abogados) ${ }^{41}$. Lo anterior constituye un argumento más en apoyo de la tesis que retiene la legitimación pasiva en el Servicio puesto que, junto a los argumentos de carácter sustantivo que se han expuesto, no puede defenderse la postura que más confusión genera objetivamente hablando. Desde el principio de la reparación integral del daño, debe rechazarse una interpretación que comprometa gravemente la reparación de las víctimas; y desde el principio de la responsabilidad del Estado, es más acorde con la evolución del derecho chileno la tesis de la legitimación pasiva del Servicios pues, en Chile, la responsabilidad de la administración se construyó sobre una

\footnotetext{
$37 \quad$ La ley entró en vigencia el 1 de enero de 2005 (artículo 18 transitorio).

38 El artículo 15 transitorio consideraba el 1 de enero de 2009 como fecha límite para que todos los hospitales allí referidos pasaran a ser Establecimientos Autogestionados. La LEY No 20.319 (2008), referida en la nota precedente, extendió el plazo hasta el 31 de enero de 2010.

39 Obtuvieron la calidad de Establecimientos de Autogestión en Red antes del 31 de enero de 2010 los siguientes once hospitales: en el año 2006, el Instituto Nacional del Cáncer, el Hospital Dr. Luis Calvo Mackenna y el Hospital de Temuco; en el año 2007, los Hospitales Dr. Luis Tisné Brousse, Instituto Nacional del Tórax y el Instituto Traumatológico Dr. Teodoro Gebauer; en el año 2008, el Hospital Herminda Martín de Chillán, el Hospital San Juan de Dios de Los Andes, el Instituto Psiquiátrico Dr. José Horwitz Barak, el Hospital El Pino y el Hospital Exequiel González Cortés.

40 Debido a que no existe un registro de Establecimeintos Autogestionados, no es fácil determinar los Hospitales que han adquirido dicha calidad aparte de los 56 que menciona la Ley y de los referidos en la nota anterior.

41 Véase la parte I, apartados 2.2 y 2.3 de este trabajo.
} 
jurisprudencia que extendió la responsabilidad civil del funcionario hacia la administración concebida como persona jurídica ${ }^{42}$.

Respecto del segundo punto referido (carencia de recursos para el pago de indemnizaciones), tampoco parece plausible el argumento de que, a fines prácticos, lo que interesa es el patrimonio que responderá y que los Establecimientos Autogestionados cuentan con un "patrimonio propio de afectación"³. Aparte de la objeción conceptual en torno a la falta de patrimonio propio que analizamos cuando nos hicimos cargo del argumento de la "personalidad delegada", el argumento debe ser también rechazado en términos prácticos si de lo que se trata es de asegurar la indemnidad de las víctimas de negligencias médicas. Y debe ser rechazado porque ese "patrimonio" no garantiza la reparación de la víctimas porque normalmente los bienes más valiosos que lo integran son inembargables ${ }^{44}$; porque la solvencia de los hospitales públicos se encuentra hoy sumamente cuestionada ${ }^{45}$; y porque los presupuestos de los Establecimientos Autogestionados no suelen asignar montos al subtítulo 26 (otros gastos corrientes) ítem 02 (compensaciones por daños a terceros y/o a la propiedad $)^{46}$.

Por todo lo anterior, pensamos que cuando el artículo 36 inciso $6^{\circ}$ del D.F.L No 1 (2005) prescribe que los Establecimientos Autogestionados "no comprometerán sino los recursos y bienes afectos al cumplimiento de sus fines propios a que se refieren los artículos 42 y 43", establece simplemente una regla de administración interna que podría servir para configurar la responsabilidad del Director del Establecimiento Autogestionado por mala gestión financiera, pero en ningún caso podría entenderse que es una restricción aplicable a las víctimas de una negligencia médica, sin conculcar gravemente los principios de derecho de daños (reparación integral) y algunos importantes bienes que gozan de protección constitucional (por ejemplo, la vida, o la integridad física y psíquica de las personas).

\footnotetext{
42 Barros (2006) p. 483.

43 Carvajal (2014) p. 147.

44 En efecto, el inciso final del artículo 43 del Decreto con Fuerza de Ley Nº 1 (2005) prescribe: "los bienes señalados en este artículo, destinados al funcionamiento de los servicios sanitarios y administrativos, gozan de inembargabilidad".

45 Este argumento cobra relevancia puesto que las mediciones realizadas en el 2016 muestran que el 38\% de los hospitales de alta complejidad no cumplió con los estándares de gestión clínica y administrativa que exige el MINSAL. Ante los datos expuestos, el Gobierno ha admitido que se requiere revisar el modelo de autogestión hospitalaria por las dificultades que muestran los recintos para controlar sus gastos. Lo anterior ha redundado en una deuda que en abril pasado llegó a \$231 mil millones de pesos. La noticia, con un ranking de los recintos peor y mejor evaluados, puede verse en el Diario LA TerCera (30/05/2017). Disponible en: http://www.latercera.com/noticia/38-los-hospitales-alta-complejidad-no-cumple-los-estandares-gestion/.

46 Véase Decreto Nº 854 (2004).
} 


\section{LOS DESARROLLOS DEL DERECHO PROCESAL TAMBIÉN AVALAN LA TESIS DE LEGITIMACIÓN PASIVA DEL SERVICIO}

\section{LA CAPACIDAD PARA SER PARTE DE LOS ÓRGANOS NO PERSONIFICADOS ES EXCEPCIONALÍSIMA}

En una perspectiva histórica, una de las razones que explican la afirmación de la personalidad jurídica del Estado fue la necesidad de someter a este y a su Administración al Derecho y a la jurisdicción. La capacidad para ser parte que se le reconoce al Estado, no es más que la forma en que se trasladó el concepto de personalidad jurídica al terreno procesal ${ }^{47}$. Como ya se ha visto, tradicionalmente, tanto la doctrina como la jurisprudencia administrativa de la Contraloría General de la República, han explicado la estructura de la Administración del Estado desde un punto de vista subjetivo, esto es, atendiendo a la personalidad jurídica del Estado y sus distintos organismos e instituciones, lo que lleva naturalmente a explicar el cuadro administrativo chileno en base a los conceptos de centralización y descentralización administrativa ${ }^{48}$.

Así, cuando el ente es descentralizado, actúa con personalidad jurídica propia, y cuando es centralizado, actúa con la personalidad jurídica del Fisco. Así las cosas, se entiende que todos los entes que integran la Administración del Estado actúan de una u otra manera personificados (integrando la personalidad del Fisco o del órgano descentralizado al cual se integran).

No obstante lo referido, el principio general que asigna la capacidad para ser parte en virtud de la personalidad ha experimentado atenuaciones, principalmente en el derecho privado, pero también respecto de entes de naturaleza pública. Es en este contexto normativo y doctrinario que cabe preguntarse si es posible reconocer la misma capacidad a aquellos órganos del Estado que por pertenecer a la Administración Central o a un organismo descentralizado (el Servicio de Salud, en nuestro caso), no tienen personalidad jurídica propia y actúan, por tanto, bajo la personalidad jurídica del Fisco o del organismo descentralizado que integran. En términos simples, cabe examinar si estos órganos pueden ocupar la posición de parte en el proceso.

En el derecho chileno se observan excepciones de carácter general, así como de carácter específicas, al principio que exige la personificación del órgano para atribuirle la capacidad de ser parte. Como excepción de carácter general, se cita la situación del recurso de protección. Respecto del mismo, la jurisprudencia ha admitido la capacidad de ser parte

47 JUAN (1998) pp. 133 y 134.

48 Silva (1995) p. 120. Hay autores como Pantoja, que rechazan el criterio tradicionalmente aceptado para describir la estructura administrativa del Estado chileno (subjetivo), por no avenirse con el diseño de la Constitución de 1980. Para el autor, la Administración habría de articularse en seis grandes circuitos administrativos: (i) el constituido por el Estado persona jurídica; (ii) el que configuran los servicios constitucionalmente autónomos; (iii) el formado por los servicios descentralizados; (iv) el de las empresas del Estado; (v) el constituido por servicios legalmente autónomos (Superintendencia y Universidades Estatales); y, (vi) el de los fondos administrativos. PANTOJA (1998) p. 159. No obstante lo anterior, parece que ambos puntos de vista encuentran sustento en la Constitución de 1980 y no se excluyen mutuamente. Sobre este último punto puede verse, GuTiérREZ (2009) p. 259. 
a sujetos o entes que, según la visión clásica, por carecer de personalidad jurídica no tendrían esa aptitud (por ejemplo, recursos contra la Contraloría General de la República) ${ }^{49}$. Nos parece que esta excepción se entiende por la especial naturaleza cautelar del recurso de protección, por lo que difícilmente puede usarse ese ejemplo para justificar el mismo trato respecto de una acción de carácter indemnizatorio.

Respecto a las excepciones específicas al principio, se mencionan situaciones en que la ley, refiriéndose de manera especial a un órgano de la administración no personificada, entiende que se puede atribuir directamente la condición o calidad de parte en el proceso ${ }^{50}$. En opinión de la doctrina especializada, nos encontramos en la última hipótesis referida cuando el ordenamiento establece en la organización interna del órgano no personificado un funcionario al que le confiere su representación judicial. Según esta doctrina, si el ordenamiento jurídico determina la "posibilidad de que el jefe superior del respectivo ente u órgano asuma la representación judicial, debe entenderse que dicho reconocimiento lleva implícita la aptitud o capacidad del órgano para ocupar la posición de parte por sí mismo" ${ }^{51}$. Se afirma que, desde un punto de vista práctico, no hay necesidad de recurrir a la personalidad jurídica del organismo en que se integra hasta que tenga lugar la ejecución de una eventual sentencia, en cuyo caso más que recurrir a la personalidad jurídica del organismo, lo que interesa es recurrir a su patrimonio.

Sin tomar en consideración el hecho de que en el contexto del ordenamiento jurídico chileno es muy difícil que un juez acceda a ejecutar un fallo en el patrimonio de una persona que no ha sido condenada (ni parte en el proceso), nos parece que hay otra fuerte razón que impide aceptar el razonamiento referido en el párrafo precedente. Se trata del hecho cierto de que -en el caso que analizamos- la ley no prescribe que el Director del Hospital es el representante judicial y extrajudicial del establecimiento, sino que consigna en términos explícitos que "para todos los efectos legales, la representación judicial y extrajudicial del Servicio se entenderá delegada en el Director del Establecimiento".

Si el hecho de que se le otorgue la representación judicial y extrajudicial de un órgano no personificado a un sujeto determinado implica darle capacidad de ser parte a ese órgano; no dársela no puede llevar a pensar que el órgano tenga capacidad de ser parte (si se usa la misma lógica). Como se verá enseguida, un correcto entendimiento del instituto de la "representación", y de la "delegación" de aquella, solo puede llevar a afirmar que la capacidad de ser parte es del Servicio de Salud, aun cuando se trate de atribuciones que han sido desconcentradas.

\section{LA DELEGACIÓN DE REPRESENTACIÓN: UNA ESPECIAL FORMA DE EMPLAZAMIENTO}

Como se ha visto más arriba, una de las reglas que se ha citado para defender la tesis de que el Establecimiento Autogestionado ostenta la legitimación pasiva, es aquella que ordena las atribuciones del Director Establecimiento ${ }^{52}$. En base a esta regla, se ha sostenido

\footnotetext{
Gutiérrez (2009) p. 262.

GutiérRez (2009) p. 262.

GutiérRez (2009) p. 266.

Artículo 36 del D.F.L No 1 (2005).
} 
que se habría dotado a los Establecimientos de una "personalidad delegada" que serviría de sustento de la legitimación pasiva ${ }^{53}$. Sin embargo, un análisis diferenciado de los conceptos involucrados (capacidad procesal, delegación y representación) no permite avalar tal conclusión y, por el contrario, sirve de mejor manera para fundamentar la tesis que defiende la legitimación pasiva de los Servicios de Salud.

Para empezar, conviene tener presente que la capacidad procesal de las personas jurídicas se ejerce a través de órganos (normalmente un funcionario especializado) que ejecutan actos en nombre del ente descentralizado. La representación orgánica indica el poder que compete a órganos externos de una persona jurídica, y se caracteriza porque el órgano representativo se identifica con la estructura de la persona; no sustituye a la entidad, sino que obra como parte integrante de ella. En términos funcionales, el recurso a la representación es indispensable en el ejercicio de actividades de alta complejidad que no permiten a una sola persona hacerse cargo de manera eficiente de la gestión de la actividad. Por lo tanto, se trata de un instrumento que permite optimizar la administración y ampliar la esfera de actuación jurídica del sujeto ${ }^{54}$.

En el caso que aquí se analiza, el único órgano con personalidad jurídica (de derecho público) que existe es el Servicio de Salud. La representación orgánica del Servicio le corresponde, por mandato del artículo 22 del D.F.L No 1 (2005), a su Director. Por lo mismo, es este órgano quien tendrá la capacidad procesal para actuar por aquel, integrando la propia estructura de su persona jurídica (el Servicio) ${ }^{55}$. En la tradición en la que se inserta el derecho chileno, es pacífica la idea de que el principal efecto de la representación es que las consecuencias del acto del representante se radican directamente en la esfera jurídica del representado ${ }^{56}$, y esta es la acepción que recoge el Código Civil en el artículo 1448: "[l]o que una persona ejecuta a nombre de otra, estando facultada por ella o por la ley para representarla, produce para el representado los mismos efectos que si hubiera contratado el mismo".

Por mandato legal, en el ordenamiento chileno no puede negarse que aquello que haga el Director del Servicio debe entenderse que lo ha hecho directamente el Servicio, pero queda por responder qué implica que se delegue esta representación en el contexto administrativo en que se mueve este trabajo. Al respecto, se ha dicho que la delegación de atribuciones o competencias es la asignación a un ente u órgano por parte de otro, del ejercicio de algunas competencias determinadas que se reconocen como propias del segundo órgano (artículo 41 LOCBGAE). Se añade que el delegado será responsable sobre la gestión de las materias delegadas; y que el delegante será responsable por el incumplimiento de sus obligaciones de control y dirección del inferior ${ }^{57}$.

En el caso que analizamos, el órgano delegante es el Director del Servicio y el órgano delegado es el Director del Establecimiento; siendo la competencia que se delega la representación judicial del Servicio de Salud, es decir, el "poder" de radicar directamente

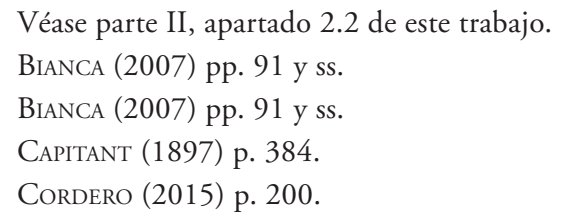


los efectos de sus actos (derechos y obligaciones) en la esfera jurídica del Servicio correspondiente. Como reza la norma, esto solo ocurrirá cuando cada uno de los Directores de los Establecimientos Autogestionados ejerza las atribuciones señaladas en el artículo 36 del D.F.L N ${ }^{\circ} 1$ (2005).

Con ese poder, los Directores del Hospital comprometerán la persona (y el patrimonio) del Servicio de Salud de que se trate, siempre que ejerzan las funciones y atribuciones que determine la ley. Dado que cambia el órgano que tiene la representación orgánica, necesariamente cambia la representación procesal y cambia la forma de emplazamiento del Servicio. En estricta concordancia con el razonamiento aquí expuesto, es que el artículo 36 termina disponiendo que la demanda se le debe notificar al Director del Establecimiento Autogestionado, y que este debe ponerla en el plazo de 48 horas en conocimiento personal del Director del Servicio de Salud correspondiente, quien podrá actuar como coadyuvante en cualquier etapa del proceso. Esta particular forma de emplazar al Servicio, por lo demás, se encuentra plenamente justificada dada la particular estructura de la red hospitalaria (es normal que, si se produce un daño en un establecimiento, sea su Director el que más información maneje), aunque no puede negarse que la referencia que la disposición hace al Director del Servicio como "coadyuvante" introduce algunas dudas sobre la legitimación pasiva: ¿trata la norma al Servicio como un tercero? ¿Indica ello que el Establecimiento es el verdadero legitimado pasivo?

A nuestro juicio, las preguntas formuladas en el párrafo anterior deben responderse negativamente. El hecho de que en estos casos el Servicio actúe representado por el Director del Hospital, unido al hecho de que la norma contenida en el artículo 36 del D.F.L. $\mathrm{N}^{\circ}$ 1 (2005) ordena al Director del Hospital poner en "conocimiento personal" del Director del Servicio de Salud correspondiente la demanda, permite sostener esta posición. Así, al actuar el Director del Hospital en representación del Servicios (por delegación legal), no puede sino concluirse que los actos de este son los actos del Servicio y que, por lo mismo, el Servicio es parte (no tercero). El que actuaría como coadyuvante/tercero (no parte) es el órgano-Director del Servicio (y no el Servicio), lo que es teóricamente posible en tanto que 'en estos casos' no actúa en representación del Servicio porque su representación ha sido legalmente atribuida al Director del Hospital (delegación legal) y, según el art. 35 del D.F.L. No 1 (2005), "el Director del Servicio de Salud no podrá interferir en el ejercicio de las atribuciones que le confiere este Título al Director del Establecimiento, ni alterar sus Decisiones".

Por todo lo anterior, pensamos que una correcta forma de entender lo hasta aquí expuesto es que, cuando el daño se produce en el ámbito de un establecimiento no Autogestionado, se debe demandar al Servicio y notificar directamente al Director del mismo; y cuando se trata de un Autogestionado, se debe demandar al Servicio, pero notificando al Director del Hospital, quien deberá notificar, a su vez, al Director del Servicio en el plazo de 48 horas. Como se ve, esta interpretación es concordante con una de las variantes jurisprudenciales que revisamos más arriba y, por lo mismo, es la que pensamos que se debe consolidar en el futuro ${ }^{58}$.

58 Véase parte I, apartado 2.3.1 de este trabajo. 


\section{CONCLUSIONES}

1. El problema a de la legitimación pasiva de los diferentes órganos del Estado que prestan servicios médicos se ha ido agudizando en la medida en que la estructura de la administración se ha ido complejizando; y con la aparición en escena en el año 2010 de los Establecimientos Autogestionados en Red (EAR), surgió la duda sobre el órgano que en el nuevo escenario debía asumir la legitimación pasiva: los Servicios de Salud o los nuevos EAR.

2. Ante la disyuntiva referida, cierto sector de la doctrina y la jurisprudencia ha defendido una interpretación normativa que le otorga la legitimación pasiva a los EAR (en lugar de a los Servicios de Salud) en los juicios de mal praxis médica: se ha presentado así uno de los problemas más recurrentes y espinosos de la disciplina.

3. En este trabajo concluimos que la hipótesis más razonable es la que sostiene que la legitimación pasiva le corresponde al Servicio de Salud, en los casos en que se juzgue la responsabilidad por daños ocurridos en las instalaciones de un EAR. Y esta conclusión llegamos en base a razones extraídas del análisis de la normativa legal, a la luz de los conceptos y principios del Derecho de Daños, el Derecho Administrativo y el Derecho Procesal chileno.

4. Desde el punto de vista de Derecho Administrativo, la legitimación pasiva le corresponde al Servicio de Salud en lugar de EAR -básicamente-, porque este último órgano no tiene personalidad jurídica (es un órgano desconcentrado).

5. Desde el punto de vista del Derecho de Daños la legitimación pasiva le debe corresponder al Servicio de Salud en lugar del EAR, porque negar esta posibilidad implicaría limitar injustificadamente el patrimonio llamado a garantizar la reparación de los daños. La forma en que el Estado se organice internamente no le puede ser oponible a las víctimas que deben ser indemnizada, salvo que se haga por las vías legalmente reconocidas, esto es, por la vías de la generación legal de un órgano con personalidad jurídica y con dotación presupuestaria propia que garantice apropiadamente las reparaciones.

6. Desde el punto de vista del Derecho Procesal, la norma contenida en el artículo 36 D.F.L. $\mathrm{N}^{\circ} 1 / 2005$ no le resta legitimación pasiva al Servicio de Salud del que forma parte el órgano desconcentrado (EAR), y el hecho de que ordene notificar al Director del EAR solo implica un cambio en la forma de realizar el emplazamiento del único sujeto con capacidad para ser imputado que se observa en el horizonte: el Servicio de Salud.

\section{BIBLIOGRAFÍA CITADA}

Alarcón, Pablo (2015): "Notas para el estudio de la desconcentración en el Derecho Administrativo chileno: antecedentes históricos”, en BocKSANG, Gabriel y LarA, José Luis (edit.), Administración territorial de Chile: estudios sobre descentralización y desconcentración administrativa (Santiago, Thomson Reuters) pp. 5-12. 
Argandoña, Manuel (1982): La organización administrativa en Chile. Bases Fundamentales (Santiago, Editorial Jurídica de Chile).

Barros, Enrique (2006): Tratado de Responsabilidad Extracontractual (Santiago, Editorial Jurídica de Chile).

Bermúdez, Jorge (2014): Derecho Administrativo General (Santiago, Thomson Reuters).

Bianca, Massimo (2007): Derecho civil, el contrato (trad. Fernando Hinestrosa y Edgar Cortés, Bogotá, Universidad del Externado).

Capitant, Henri (1897): Introduction à l'étude du Droit Civil (Paris, Pedone, quinta edición).

Carvajal, Carolina (2014): "Legitimación pasiva de los hospitales autogestionados", Revista de Derecho, Escuela de Postgrado, № 6: pp. 137-158.

Cárdenas, Hugo y Moreno, Jaime (2011): Responsabilidad médica: estándares jurisprudenciales de la falta de servicio (Santiago, LegalPublishing).

Cea, José Luis (1999): El sistema constitucional de Chile. Sintesis crítica (Valdivia, Editorial Universidad Austral).

Cordero, Luis (2015): Lecciones de Derecho Administrativo (Santiago, Thomson Reuters, primera edición).

Domínguez, Ramón (2010): "Límites al principio de reparación integral”, Revista Chilena de Derecho Privado, N 15: pp. 9-28.

Fernández, Emilio (1981): Diccionario de Derecho Público. Administrativo - Constitucional Fiscal (Buenos Aires, Editorial Astrea).

GutiérRez, José Ramón (2009): "El presupuesto procesal de la capacidad de las personas jurídicas, en especial las de derecho público", Revista Chilena de Derecho, vol. XXVI, Nº 2: pp. 245-279.

Huepe, Fabián (2006): Responsabilidad del Estado, falta de servicio y responsabilidad objetiva en su actividad administrativa (Santiago, LexisNexis).

Huidobro, Ramón (2011): Tratado de Derecho Administrativo. Derecho y Administración Comunal, Tomo III (Buenos Aires, Abeledo Perrot).

Inostroza, Manuel y Nancuante, Ulises (2013): "La experiencia chilena de administrar los Hospitales Autogestionados en Red 2005-2012: ¿un instrumento consolidado y definitivo o una transición a un nuevo tipo de prestador público, para una nueva etapa de la Reforma de Salud?”. Disponible en: http://95propuestas.cl/site/wp-content/ uploads/2013/05/la-experiencia-chilena-de-administrar-los-hospitales-autogestionados-en-red-manuel-inostroza-y-ulises-nancuante.pdf.

Juan, Ricardo (1998): Las comunidades autónomas en el proceso civil (Granada, Comares).

Nancuante, Ulises; Romero, Andrés y Sotomayor, Roberto (2012): Régimen jurídico de la salud (Santiago, Thomson Reuters).

Pantoja, Rolando (1998): La Organización Administrativa del Estado (Santiago, Editorial Jurídica de Chile).

Parejo, Luciano (2016): Lecciones de Derecho Administrativo (Madrid, Editorial Tirant lo Blanch, octava edición).

Pizarro, Carlos (2017): La responsabilidad civil médica (Santiago, Thomson Reuters). 
Ponce de León, Sandra (2015): "Bases de la organización administrativa en Chile. Principios, Normas y Estado Actual”, en Bocksang, Gabriel y Lara, José Luis (edit.), Administración territorial de Chile: estudios sobre descentralización y desconcentración administrativa (Santiago, Thomson Reuters) pp. 39-85.

Precht, Alejandra; Reyes, Sonia y Salamanca, Carola (2017): El ordenamiento territorial en Chile (Santiago, Ediciones Universidad Católica).

Santa María, Juan Alfonso (2016): Principios de Derecho Administrativo General (Madrid, Editorial Tirant lo Blanch).

SiLva, Alejandro (1997): Tratado de derecho constitucional, Tomo I (Santiago, Editorial Jurídica de Chile).

Silva, Enrique (1995): Derecho Administrativo chileno y comparado. El Servicio Público (Santiago, Editorial Jurídica de Chile, quinta edición).

Soто, Eduardo (1989): "La delegación en el derecho administrativo chileno (nociones fundamentales)", Revista de Derecho Público, Universidad de Chile, No 45-46: pp. 115-147.

Soто, Eduardo (1992): "La desconcentración en el derecho administrativo chileno", Revista de Derecho Público, Universidad de Chile, No 51-52: pp. 103-125.

Sото, Eduardo (2009): Derecho Administrativo. Temas fundamentales (Santiago, Editorial AbeledoPerrot - Legal Publishing, primera edición).

Tobar, Manuel (2012): Tratado de Derecho Administrativo. Derecho y administración Regional (Santiago, Editorial AbeledoPerrot - LegalPublishing).

Valdivia, José Miguel (2005): "Nuevas fronteras de la falta de servicio", Gaceta Jurídica, No 301: pp. 7-25.

\section{NORMAS CITADAS}

Constitución Política de la República de Chile (24/10/1980).

Decreto con Fuerza de Ley No 1 (7/8/1993), Fija el texto refundido, coordinado y sistematizado de la Ley Orgánica del Consejo de Defensa del Estado.

Decreto con Fuerza de Ley N ${ }^{\circ} 1$ (24/4/2006), Fija texto refundido, coordinado y sistematizado del Decreto Ley $\mathrm{N}^{\circ} 2.763$, de 1979 y de las Leyes $\mathrm{N}^{\circ} 18.933$ y $\mathrm{N}^{\circ} 18.469$.

DECRETO No 854 (2/12/2004), Determina clasificaciones presupuestarias.

Ley N ${ }^{\circ} 18.575$ (5/12/1986), Ley Orgánica Constitucional de Bases Generales de la Administración del Estado.

Ley N $\mathrm{N}^{\circ} 18.695$ (31/3/1988), Ley Orgánica Constitucional de Municipalidades.

LEY N 19.937 (24/2/2004), Modifica el D.L. No 2.763, de 1979, con la finalidad de establecer una nueva concepción de la autoridad sanitaria, distintas modalidades de gestión y fortalecer la participación ciudadana.

LEY N 20.319 (31/12/2008), Modifica la Ley $N^{\circ}$ 19.937, impidiendo que los establecimientos de salud no calificados como de autogestión en red al 1 de enero de 2009, pasen a tener dicha calidad por el solo ministerio de la ley.

LEY No 20.529 (27/08/2011), Sistema nacional de aseguramiento de la calidad de la educación parvularia, básica y media y su fiscalización. 


\section{JURISPRUDENCIA CITADA}

Castillo Alonso con Fisco (2005): Corte de Apelaciones de Santiago, 14 de abril de 2005, rol No 6974-2001, en www.pjud.cl, fecha de consulta 20 de agosto de 2017.

Lepe Alarcón con SeRVICIO de Salud ConcepCión (2013): $1^{\text {er }}$ Juzgado Civil de Concepción, 20 de mayo de 2013, rol No C-5304-2012, en www.pjud.cl, fecha de consulta 20 de agosto de 2017.

García Rivera y otra con Servicio de Salud Metropolitano Oriente, Hospital Luis Calvo MACKENNA Y LUIS TISNÉ (2014): Corte de Apelaciones de Santiago, 20 de enero de 2014, rol No C-888-2013, en www.pjud.cl, fecha de consulta 20 de agosto de 2017.

Contreras VÁsquez y otra con Hospital Barros Luco Trudeau (2014): Corte de Apelaciones de San Miguel, 22 de enero de 2014, rol No 2292-2013, en www.pjud.cl, fecha de consulta 20 de agosto de 2017.

Contreras VÁsquez y otra con Hospital BarRos Luco Trudeau (2014): Corte Suprema, 15 de abril de 2014, rol No 6478-2014, en www.pjud.cl, fecha de consulta 20 de agosto de 2017.

Pareja Ceballos con Servicio de Salud Talcahuano (2014): Corte de Apelaciones de Concepción, 29 de diciembre de 2014, rol No 1068-2014, en www.pjud.cl, fecha de consulta 20 de agosto de 2017.

Cárcamo Alarcón Juan Carlos con Servicios de Salud (2014): Corte de Apelaciones de Puerto Montt, 30 de diciembre de 2014, rol No 429-2014, en www.pjud.cl, fecha de consulta 20 de agosto de 2017.

Campos Godoy y otros con Servicio de Salud Metropolitano (2015): Corte Suprema, 1 de junio de 2015, rol No 3148-2015, en www.pjud.cl, fecha de consulta 20 de agosto de 2017.

Lepe Alarcón con Hospital San José Coronel (2015): $1^{\text {er }}$ Juzgado Civil de Coronel, 12 de junio de 2015, rol No C-183-2014, en www.pjud.cl, fecha de consulta 20 de agosto de 2017.

De la Fuente con SeRVicio de Salud Concepción (2015): Corte de Apelaciones de Concepción, 13 de julio de 2015, rol No 485-2015, en www.pjud.cl, fecha de consulta 20 de agosto de 2017.

Triviño Gutiérrez Jorge con SerVicio de Salud del Reloncaví (2015): Corte de Apelaciones de Puerto Montt, 13 de julio de 2015, rol No 1016-2014, en www.pjud.cl, fecha de consulta 20 de agosto de 2017.

Araya Castillo con Servicio de Salud II Región de Antofagasta (2015): Corte de Apelaciones de Antofagasta, 8 de octubre de 2015, rol No 743-2015, en www.pjud.cl, fecha de consulta 20 de agosto de 2017.

Arrau Henríquez con Hospital del Salvador, Servicio de Salud Metropolitano (2016): Corte Suprema, 9 de junio de 2016, rol No 14909-2015, en www.pjud.cl, fecha de consulta 20 de agosto de 2017.

Gonzalez con Servicio de Salud Metropolitano Occidente (2016): Corte de Apelaciones de Santiago, 24 de junio de 2016, rol No 2933-2016, en www.pjud.cl, fecha de consulta 20 de agosto de 2017 . 
Lepe Alarcón con Hospital San José Coronel (2016): Corte de Apelaciones de Concepción, 7 de julio de 2016, rol No 2097-2015, en www.pjud.cl, fecha de consulta 20 de agosto de 2017.

Muñoz Torres y otro con Hospital Base Puerto Montt (2016): Corte Suprema, 12 de diciembre de 2016, rol No 27985-2016, en www.pjud.cl, fecha de consulta 20 de agosto de 2017.

Saldías Araya Elsa Pablina y otros con Servicio de Salud Metropolitano Oriente y otros (2016): Corte de Apelaciones de Santiago, 21 de diciembre de 2016, rol No 78792016, en www.pjud.cl, fecha de consulta 20 de agosto de 2017.

Saldías Araya Elsa Pablina y otros con Servicio de Salud Metropolitano Oriente y otros (2017): Corte Suprema, rol No 11759-2017, en www.pjud.cl, fecha de consulta 8 de septiembre de 2017. 